\title{
Analisis Performansi Protokol Routing Vehicular Network Menggunakan Algoritma Ant Colony Jamak
}

\author{
Muhammad Sayutia ${ }^{\mathrm{a}}$, Ramzi Adriman ${ }^{\mathrm{a} 2}$, Nasaruddin ${ }^{\mathrm{a} 3}$ \\ a Program Studi Magister Teknik Elektro, Universitas Syiah Kuala \\ Jl. Tgk. Syech Abdurrauf, No. 7 Darussalam, Banda Aceh 23111, INDONESIA \\ ${ }^{1 \mathrm{~m}}$. sayuti.comegmail.com \\ 2ramzi.adriman@unsyiah.ac.id \\ ${ }^{3}$ nasaruddin@unsyiah.ac.id
}

\begin{abstract}
Abstrak
Pengembangan teknologi jaringan ad-hoc disebut Vehicular Ad-hoc Network (VANET). VANET terbentuk dari kumpulan node yang menggunakan antarmuka nirkabel untuk dapat melakukan komunikasi antara satu node dengan node lainnya. Penelitian ini, membangun sebuah protokol routing dengan menggunakan algoritma Ant Colony yang diberi nama (ANTC), dimana akan dibandingkan dengan routing protokol Ad-Hoc On-Demand Distance Vector (AODV) untuk melihat performansi dari masing - masing routing protocol. Proses routing AODV dengan membentuk sebuah pergerakan dari satu nodesumber ke node tujuan berdasarkan pada permintaan node sumber tersebut. Sedangkan proses routing ANTC, setiap node menyimpan memori yang berisi informasi pergerakan pada setiap node yang diketahuinya, informasi pergerakan akan diperbaharui secara berkala jika terjadi perubahan link. Parameter kinerja routing protokol yang diukur berupa Latency dan Througphut. Hasil yang diperoleh pada penelitian ini adalah routing protokol ANTC unggul pada nilai parameter Latencydengan nilai rata-rata 16,8 s dan Througphut dengan nilai rata-rata 87,758 Kbps.
\end{abstract}

\section{Performance Analysis of The Vehicular Network Routing Protocol Using The Plural Ant Colony Algorithm}

\begin{abstract}
The development of ad-hoc network technology is called the Vehicular Ad-hoc Network (VANET). VANET is formed from a collection of nodes that use a wireless interface to be able to communicate between one node and another. This research, build a routing protocol using the Ant Colony algorithm named (ANTC), which will be compared with the Ad-Hoc On-Demand Distance Vector (AODV) routing protocol to see the performance of each routing protocol. The AODV routing process by forming a movement from one source node to the node based on the source node's request. While the ANTC routing process, each node stores a memory containing information on the movement of each node it knows about, the information will move periodically if there is a link change. Routing protocol performance parameters measured are Latency and Througphut. The results obtained from this study are the ANTC routing protocol is superior in the latency value parameter with an average value of $16.8 \mathrm{~s}$ and Througphut with an average value of 87,758 kbps.
\end{abstract}

Keywords : VANET, Ant Colony, AODV, QoS

\section{Pendahuluan}

Saat ini perkembangan teknologi informasi dan komunikasi menjadi salah satu indikator kemajuan manusia. Salah satunya teknologi komunikasi antar kendaraan yang disebut dengan Vehicular Ad Hoc Network (VANET). VANET termasuk dalam jaringan komunikasi nirkabel dan merupakan subkelas dari Mobile Ad Hoc Network (MANET).
Saat ini perkembangan teknologi informasi dan komunikasi menjadi salah satu indikator kemajuan manusia.

Jaringan VANET adalah suatu jaringan Ad Hoc yang digunakan untuk berkomunikasi antara kendaraan satu dengan kendaraan lainnya dengan kata lain disebut juga dengan Vehicle to Vehicle Communication (V2V) [1].

Salah satu performasi jaringan komunikasi antar kendaraan tergantung pada kinerja protokol routing. Transmisi data yang rendah mengakibatkan komunikasi 
antar kendaraan pada lingkungan VANETs juga semakin memburuk. Hal ini dikarenakan posisi kendaraan yang selalu berubah. Maka topologi yang tercipta selalu berubah sesuai mobilitas kendaraan tersebut. Dengan menggunakan Algoritma Ant colony yang merupakan salah satu metode metaheuristik dengan menerapkan semut sebagai agen dengan mengupdate pheromone-nya untuk dapat melakukan proses pencarian solusi yang efektif dan efesien sehingga menghasilkan routing protocol.

Pada VANET fungsi routing dilakukan oleh routing protocol, dimana routing protocol dapat melakukan adaptasi terhadap pergerakan node dan trafik yang diakibatkan oleh pergerakan node secara acak. Routing berkerja di lapisan network yang merupakan suatu mekanisme untuk menentukan pergerakan dari source node menuju destination node. Perumusan masalah untuk penelitian ini, bagaimana mengetahui proses simulasi routing yang ada pada lingkungan VANET dan performansi dari routing protocol, maka diperlukan sebuah simulasi.

Penelitian ini telah membangun sebuah routing protocol menggunakan algoritma Ant Colony yang telah disesuaikan dan dapat dijalankan pada network simulator NS-2. network simulator NS-2 merupakan wadah untuk mengembangkan algoritma Ant Colony agar dapat diimplementasikan. Dan selanjutnya di proses dengan coding analisis sehingga menghasilkan parameter uji Latency dan Throughput dari routing protocol AODV, routing protocol ANT dan routing protocol ANTC.

Penelitian terkait dilakukan oleh [3] melakukan penelitian menggunakan protocol AODV dan DSR untuk dibandingkan kinerja keduanya dengan lingkungan simulasi yang telah ditentukan. Simulator yang digunakan adalah OPNET Modeler 14.5. Kinerja protocol yang diukur menggunakan parameter uji jitter, throughput, latency dan packet loss. Hasil penelitian menunjukkan bahwa AODV memberikan kinerja yang lebih baik dibanding DSR.

Penelitian yang berjudul "Performance Improvement of Dynamic Source Routing (DSR) Protocol using Ant Colony Optimization for Vehicular Ad-hoc Network (VANET) " [2] yaitu melakukan analisis terhadap protokol routing DSR standar dengan protokol routing DSR yang telah dimodifikasi dengan menggunakan algoritma semut (DSRAnt). Prameter uji coba yang dihitung yaitu Delay, jitter, konsumsi energi, routing load dan Packet Delivery Ratio. Hasil menunjukan bahwa DSR-Semut lebih unggul dibandingkan DSR standar dilihat dari metric performasi Delay 2,25 ms, jitter 1,2 ms, routing load 0,36 Kbps, dan PDR $83,5 \%$. Sedangkan DSR standar hanya unggul pada metrik perfomansi konsumsi energy yaitu 15,75 Joule.

Algoritma Ant colony merupakan salah satu metode metaheuristik yang menerapkan semut sebagai agen dengan mengupdate pheromone-nya untuk dapat melakukan proses pencarian solusi yang efektif dan efesien. Pada sebuah kasus, algoritma ini diusulkan untuk mencapai penjadwalan tugas dengan beban yang berbeda-beda, dengan banyaknya semut yang bertukar informasi untuk menemukan solusi secara bersama-sama untuk meminimalkan waktu pelaksanaan tugas yang ingin dicapai dan mampu mendapatkan solusi dengan efektif dan efesien.
Pada kasus lainnya, algoritma ini dibentuk menjadi 2 koloni, yang dimana koloni pertama bertugas untuk meminimalisir node sedangkan koloni yang kedua bertugas meminimalisir waktu perjalanan dan juga mendapatkan solusi yang sama [9].

\section{Metedologi Penelitian}

\section{A. Alur Penelitian}

1) Studi Literatur Routing protocol: Tahap studi literatur merupakan tahap pencarian dan pengumpulan literatur-literatur dan kajian- kajian yang berkaitan dengan masalah-masalah yang ada pada penelitian ini, baik berupa artikel, buku referensi, internet, dan sumber-sumber lain yang berhubungan dengan masalah pada penelitian.

2) Desain Pengembangan Algoritma Ant Colony: Tahapan pengembangan Algoritma Ant Colony yang dilakukan yaitu identifikasi parameter Algoritma Ant Colony. Pada tahap ini menganalisa faktor - faktor apa saja yang mempengaruhi kinerja jaringan antara vehicle to vehicle $(\mathrm{V} 2 \mathrm{~V})$

3) Implementasi Algoritma Ant Colony pada NS-2: Implementasi algoritma Ant Colony pada NS-2 dilakukan sesuai metode penambahan model algoritma baru pada routing protocol dengan tahapan-tahapan sebagai berikut :

- Identifikasi fungsionalitas (functionality) yang diperlukan untuk implementasi model algoritma Ant Colony dan attribute pada NS-2.

- Identifikasi bagian code yang dapat digunakan kembali (reusability) dari model routing protocol yang tersedia saat ini.

- Identifikasi dependensi (dependencies) yang diperlukan untuk coding Ant Colony yang akan dibuat.

- Evaluasi coding style NS-2 untuk implementasi Ant Colony.

- Penulisan coding untuk implementasi pada fungsi NS-

- Pengujian implementasi coding algoritma Ant Colony menggunakan $A W K$.

4) Pengecekan Error Simulasi: Setelah tahapan implementasi dilakukan, selanjutnya dilakukan simulasi pada NS-2, dimana simulasi harus sesuai dengan tujuan yang diharapkan, jika program Algoritma nya masih belum sesuai tujuan, maka proses simulasi akan diulangi kembali untuk mencapai hasil yang diinginkan.

5) Pengujian Algoritma: Pada tahap pengujian Algoritma, hasil yang telah didapat dari proses simulasi akan dianalisis dan dapat diambil kesimpulan. Bagaimana kinerja dari komunikasi vanet vehicle to vehicle (V2V) dan pengaruh pada kondisi routing.

6) Analisi Latency dan Througphut: Setelah tahapan pengujian algoritma dilakukan, selanjutnya dilakukan pembuatan node, dimana menentukan skenario mobilitas dan aktifitas node pada tahap awal diperlukan, sehingga dapat digunakan dan diterapkan pada sebuah routing yang akan dilakukan pengujian. Selanjutnya akan di simulasikan menggunakan NS-2 hingga menghasilkan output file yang 
diharapkan. Selanjutnya setelah menghasilkan output akan dianalisis menggunakan file AWK yang sudah disesuaikan untuk dapat menghasilkan parameter uji yang diharapkan. Parameter uji yang digunakan yaitu :

a) Latency : Merupakan durasi waktu antara mengirim informasi dari pengirim sampai diterima oleh penerima. Secara umum latency dinyatakan pada persamaan 1 dengan rumus sebagai berikut.

$$
\text { Latency }=\text { waktu terima }- \text { waktu kirim }
$$

b) Throughput : Salah satu istilah yang mendefinisikan banyaknya bit yang diterima dalam selang waktu tertentu. Secara umum throughput dinyatakan pada persamaan 2 dengan rumus sebagai berikut.

Throughput $=\frac{\text { Jumlah total packet yang berhasil dikirim }}{\text { total } \text { waktu pengamatan }}$

\section{B. Algoritma Ant Colony}

Algoritma Ant Colony merupakan Algoritma yang terinspirasi oleh perilaku semut dalam menemukan rute dari sarang menuju sumber makanan. Semut mampu mengindra lingkungannya yang kompleks mencari makanan dan kemudian kembali ke sarangnya dengan meninggalkan zat pheromone pada jalur-jalur yang mereka lalui. Dengan adanya pheromone inilah semut dapat menemukan jalur tercepat menuju sumber makanan. pheromone merupakan zat kimia yang berasal dari kelenjar endokrin dan digunakan oleh makhluk hidup untuk mengenali sejenisnya (satu spesies). Pada semut meninggalkan jejak kaki untuk sebagai penanda untuk mengingat jalan pulang maupun berkomunikasi dengan koloninya [10].

Pada algoritma ini biasanya akan dibentuk beberapa colony semut atau sering disebut Ant Colony Jamak yang memiliki tugas berbeda antara colony semut lainnya. Pada sebuah kasus, algorittma ini diusulkan untuk mencapai penjadwalan tugas dengan beban yang berbeda-beda, dengan banyaknya semut yang bertukar informasi untuk menemukan solusi secara bersama-sama untuk meminimalkan waktu pelaksanaan tugas yang ingin dicapai dan mampu mendapatkan solusi dengan efektif dan efesien. Pada kasus lainnya, algoritma ini dibentuk menjadi 2 koloni, yang dimana koloni pertama bertugas untuk meminimalisir kendaraan sedangkan koloni yang kedua bertugas meminimalisir waktu perjalanan dan juga mendapatkan solusi yang sama [8].

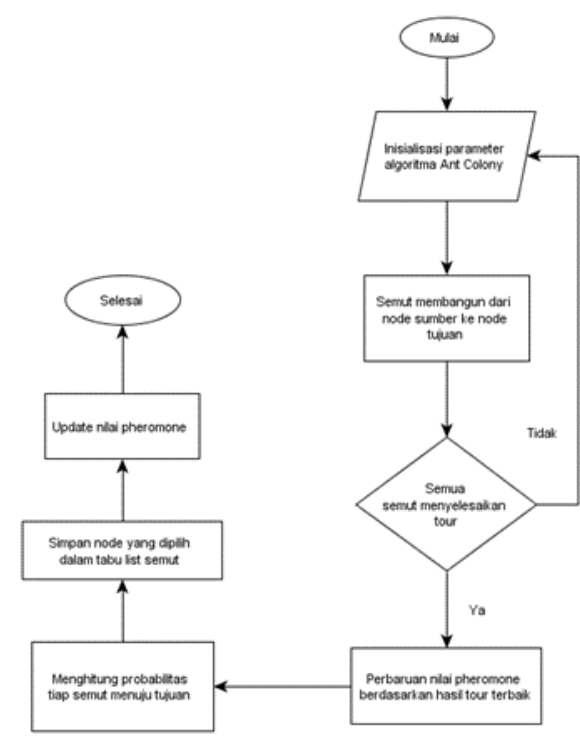

Gambar 1. Diagram alur algoritma ant colony

Pada gambar 1 merupakan diagram alur dari Algoritma Ant Colony yang digunakan. Berikut adalah penjelasan dari masing-masing tahap :

1. Menginisialisasi Parameter Algoritma Ant Colony yang meliputi : Intensitas pheromone, Parameter pengendali intensitas pheromone, parameter pengendali visibilitas, Jumlah Semut, paramter penguapan pheromone, jumlah siklus maksimum.

2. Semut akan melakukan tour nya dengan memilih node selanjutnya. Dalam memilih node selanjutnya, semut menggunakan aturan transisi status untuk menentukan aturan transisi yang digunakan

3. Semua semut menyelesaikan tour yang telah dibangun lanjut ke tahapan pembaruan nilai pheromone berdasarkan hasil terbaik, apabila tour tidak selesai maka kembali ke tahapan inisialisasi parameter algoritma Ant Colony.

4. Setelah didapatkan tour terbaik, kemudian dilakukan pembaharuan pheromone pada isi tabu list semut dengan tour terbaik tersebut. Pembaharuan pheromone ini dimaksudkan agar kadar pheromone pada sisi tour terbaik semut tersebut mengalami penguatan dan sisi yang tidak menjadi bagian tour terbaik mengalami penguapan. Sehingga, pada siklus berikutnya pencarian lebih terarah. Isi tabu list tour terbaik tersebut di simpan kedalam tabu list rute terbaik yang kemudian dilakukan kembali proses pencarian pada siklus selanjutnya dengan nilai pheromone yang telah di perbaharui pada prsoes pembaharuan pheromone.

5. Selanjutnya menghitung probabilitas route tiap semut menuju node tujuan. Koloni semut yang sudah terdistribusi ke setiap node, akan mulai melakukan perjalanan dari node pertama masing-masing sebagai node asal dan salah satu node lainnya sebagai node tujuan.

6. Setelah didapatkan node yang dituju maka selanjutnya dilakukan proses penyimpanan node tersebut ke dalam tabu list. Tabu list ini digunakan 
sebagai memori bagi semut untuk menyimpan hasil pencarian rutenya. Selain itu juga mencegah semut untuk mengujungi node yang telah dilewati.

7. Setelah route dari semut sumber hingga ke node tujuan dari siklus pertama ditemukan, maka dilakukan pembaharuan pheromone atau update pheromone. Koloni semut akan meninggalkan jejakjejak pheromone pada lintasan antar node yang dilaluinya. Adanya penguapan dan perbedaan jumlah semut yang lewat, menyebabkan kemungkinan terjadinya perubahan intensitas jejak pheromone semut antar node.

8. Setelah proses pencarian selesai maka akan terlihat pada sisi pheromone tour terbaik akan mengalami penguatan. Jalan atau sisi yang menjadi tour terbaik inilah yang akan ditampilkan sebagai hasil pencarian rute tercepat.

\section{Pengembangan Algoritma Ant Colony}

Algoritma Ant Colony merupakan algoritma yang terinspirasi oleh perilaku semut dalam menemukan rute dari sarang menuju sumber makanan, pengembangan dilakukan dengan tahapan - tahapan menentukan route yang akan diambil dari node sumber menuju node tujuan.

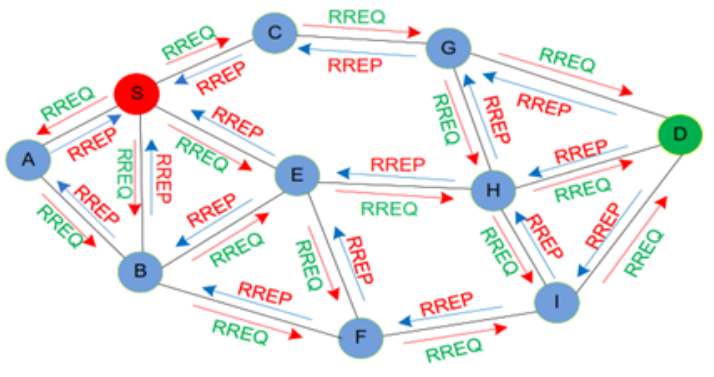

Gambar 2. Ilutrasi node sumber ke node tujuan

Pada gambar 2 adalah proses menentukan node sumber menuju node tujuan akan di terapkan pada pengembangan sebuah routing protocol menggunakan algoritma Ant Colony dan routing protocol AODV. Ilutrasi pencarian route pada routing protocol sebagai berikut :

\section{Routing Protocol AODV}

Tahapan pencarian route pada routing protocol AODV, diantaranya sebagai berikut :

a) Di saat node sumber (S) membutuhkan suatu rute menuju node tujuan (D), tahap awal yang dilakukan oleh node sumber adalah menyiarkan paket route request (RREQ) menuju node tetangganya.

b) Apabila node yang menerima RREQ memiliki informasi rute menuju node tujuan, maka node tersebut akan mengirim paket RREP kembali menuju node sumber melalui reverse path yang diciptakan RREQ setiap kali flooding dilakukan. Namun, jika node yang menerima RREQ tidak memiliki informasi rute menuju node tujuan, maka node tersebut akan menyiarkan ulang RREQ ke node tetangganya.

c) Node yang menerima RREQ dengan nilai source address dan broadcast ID yang sama dengan RREQ yang diterima sebelumnya, akan mempertahankan
RREQ yang sudah diterima di awal dan membuang RREQ baru.

d) Ketika sebuah node yang memiliki informasi rute menuju node tujuan menerima RREQ, maka node tersebut akan melakukan perbandingan antara nilai destination sequence number yang dia miliki dengan nilai destination sequence number yang ada di RREQ berdasarkan nilai yang lebih besar. Apabila nilai destination sequence number yang ada di RREQ lebih besar dari nilai yang dimiliki oleh node maka paket RREQ tersebut akan disiarkan kembali ke node tetangganya, namun apabila nilai destination sequence number yang ada di node lebih besar atau sama dengan nilai yang ada di RREQ maka node tersebut akan mengirim route reply (RREP) menuju node sumber menggunakan reverse path.

e) Apabila terjadi masalah pada rute, route maintenance yang digunakan untuk mendeteksi kerusakan rute akan mengirimkan paket route eror (RERR) menuju source node dan source node akan kembali menyiarkan paket route request (RREQ) dalam proses route discovery.

f) Informasi timeout (masa aktif rute) diinformasikan oleh Intermediate node yang menerima RREP, dan informasi rute sumber ke tujuan akan dihapus apabila waktu timeout telah habis [7].

\section{Routing Protocol ANTC}

Tahapan pencarian route pada routing protocol ANTC, diantaranya sebagai berikut:

a) Saat node sumber (S) membutuhkan suatu rute menuju node tujuan (D), tahap awal yang dilakukan oleh node sumber adalah menyiarkan paket routing request (RREQ) menuju node tetangganya.

b) Setiap node yang menerima RREQ akan meng-update informasi jalur menuju pengirim di dalam routing cache-nya, menambahkan alamatnya ke dalam paket RREQ dan kemudian akan mengirim RREQ tersebut menuju tetangganya.

c) Apabila node yang menerima RREQ memiliki informasi rute menuju node tujuan, maka node tersebut akan mengirim paket RREP kembali menuju node sumber melalui reverse path yang diciptakan RREQ setiap kali flooding dilakukan. Namun, jika node yang menerima RREQ tidak memiliki informasi rute menuju node tujuan, maka node tersebut akan menyiarkan ulang RREQ ke node tetangganya.

d) Apabila terjadi masalah pada rute, routing maintenance yang digunakan untuk mendeteksi kerusakan rute akan mengirimkan paket routing error (RERR) menuju source node dan source node akan memeriksa cache route apakah masih ada rute cadangan yang dapat digunakan. Route request akan kembali disiarkan apabila tidak terdapat rute pada cache route untuk discovery route.

\section{Pendefinisian Parameter Routing Protocol}

Setelah tahapan pengembangan algoritma Ant Colony dilakukan pada simulasi NS-2 tidak mengalami kegagalan ataupun pesan error, selanjutnya dilakukan pendefinisian berdasarkan : 
1) Pendefinisian variabel global: memiliki tujuan untuk mendefinisiakan nilai dari parameter yang akan digunakan sekaligus untuk memodelkan karakteristik pada jaringan VANET untuk routing protocol.

2) Inisialisasi: proses yang digunakan untuk menginisialisasikan variabel umum yang akan digunakan pada simulasi.

3) Pengaturan parameter node: Sebelum pembuatan node terlebih dahulu perlu melakukan pengaturan terhadap parameter-parameter dari node. Konfigurasi node yang diperlukan yaitu protokol Ad Hoc, link layer, link MAC, propagasi, ifq, layer fisik, antena, kanal, topografi, trace dan model kesalahan.

4) Pembuatan node: Setelah melakukan pengaturan pada parameter - parameter node selanjutnya adalah membuat node.

5) Pembuatan aliran trafik: aliran trafik digunakan untuk mensimulasikan proses terjadinya pengiriman dan penerimaan data dari suatu node ke node yang lain. Pada aliran trafik ini juga dapat ditentukan jenis transport agent yang digunakan

6) Mengakhiri program: untuk menghentikan program simulasi maka waktu henti yang menandakan simulasi telah berakhir harus ditetapkan dan selain itu node juga harus diatur ulang (reset).

\section{E. Pengujian Routing Protokol}

Pengujian dilakukan untuk membandingkan performansi dari routing protocol AODV, routing protocol ANT dan routing protocol ANTC pada skenario simulasi. Simulasi dilakukan dengan pengujian jumlah 10 node sampai 50 node serta dilakukan pengujian dengan kecepatan pergerakan node dari $10 \mathrm{~m} / \mathrm{s}$ sampai $50 \mathrm{~m} / \mathrm{s}$.

Dalam pengujian routing protocol ini menggunakan transmission 250 meter dengan mengirimkan paket TCP ukuran 1500 byte ke Accest Point. Simulasi di lakukan pada routing protocol AODV, routing protocol ANT dan routing protocol ANTC sebagai pembanding untuk mengeveluasi kinerja masing-masing routing protocol terhadap hasil pengujian Latency dan Throughput.

Untuk melakukan simulasi VANET pada NS-2, dibutuhkan sebuah file OTcl yang berisi deskripsi dari lingkungan simulasi. File tersebut berisikan pengaturan untuk setiap node dan beberapa event yang perlu diatur agar berjalan pada waktu tertentu.

Area simulasi yang akan dilakukan pengujian untuk routing protocol AODV, routing protocol ANT dan routing protocol ANTC, dimana pengujian dengan 10 node menggunakan area simulasi $\mathrm{x}=1500$ dan $\mathrm{y}=1500$ sampai dengan pengujian 50 node dari area simulasi $\mathrm{x}=1500$ dan $y=1500$ dan waktu simulasi 60 detik dari setiap pengujian.

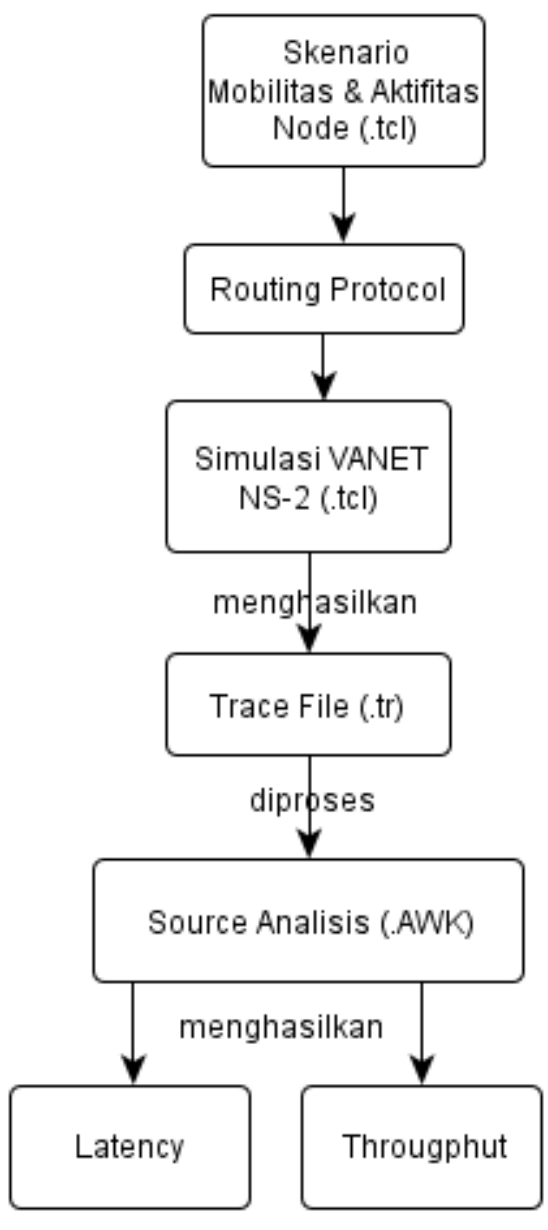

Gambar 3. Tahapan pengujian latency \& througphut

Pada gambar 3 menjelaskan tahapan - tahapan dalam melakukan simulasi, dimana menentukan skenario mobilitas dan aktifitas node pada tahap awal diperlukan, sehingga dapat digunakan dan diterapkan pada sebuah routing protocol yang akan dilakukan pengujian. Selanjutnya akan di simulasikan menggunakan NS-2 hingga menghasilkan output file yang diharapkan. Selanjutnya setelah menghasilkan output akan dianalisis menggunakan file AWK yang sudah disesuaikan untuk dapat menghasilkan latency dan trougphut yang diharapkan.

\section{HASIL DAN PEMBAHASAN}

Berdasarkan ujicoba yang dilakukan pada penelitain ini untuk menilai analisi peformansi dari protocol routing AODV dan ANTC yang digunakan dibutukannya suatu parameter ujicoba. Berikut ini merupakan analisis dari parameter ujicoba yang digunakan pada penelitan :

\section{A. Latency}

Latency adalah durasi waktu antara mengirim informasi dari pengirim sampai ke diterima oleh penerima. Latency dipengaruhi oleh kecepatan dari media transmisi (kabel koaksial, fiber optik, gelombang radio) dan delay transmisi oleh komponen jaringan seperti router, modem, hub, dan lainnya. Latency dan throughput adalah dasar dari 
pengukuran kinerja suatu jaringan. Latency mengukur waktu yang dibutuhkan dari mulai pengiriman sampai selesai, sedangkan throughput adalah waktu keseluruhan dari seluruh proses yang dalam waktu tertentu [8].

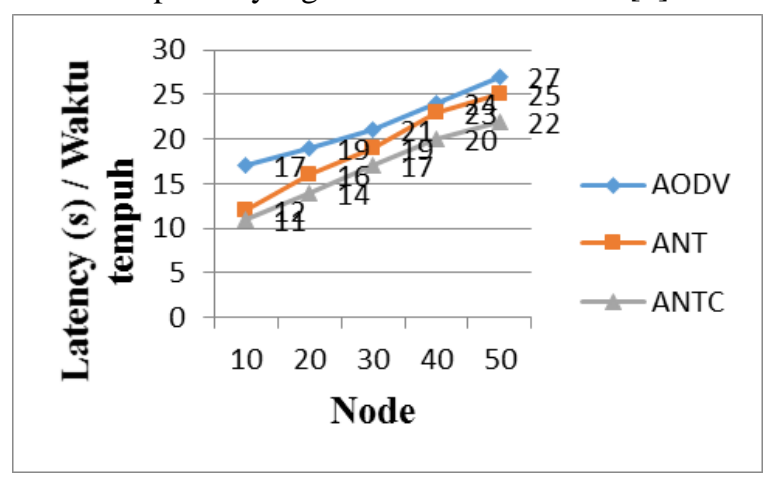

Gambar 4. Hasil pengujian latency

Pada gambar 4 menunjukan hasil pengujian protokol routing vehicular network dengan parameter uji latency, dimana pengujian latency untuk menentukan durasi waktu antara pergerakan node sumber menuju node tujuan. Dilihat dari pengujian gambar 4.19 menjelaskan routing protocol ANTC lebih unggul dengan nilai latency rata rata $16,8 \mathrm{~s}$, pada routing protocol ANT memiliki nilai latency rata - rata $19 \mathrm{~s}$ dan routing protocol AODV memiliki nilai latency rata - rata 21,6s.

\section{B. Througphut}

Throughput merupakan suatu istilah yang mendefinisikan banyaknya bit yang diterima dalam selang waktu tertentu dengan satuan bit per second yang merupakan kondisi data rate sebenarnya dalam suatu jaringan.

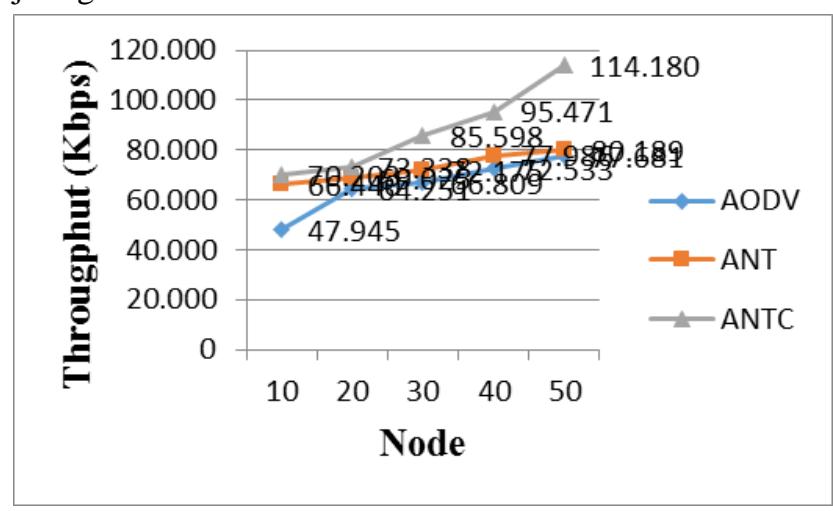

Gambar 5. Hasil pengujian througphut

Pada gambar 5 menunjukan hasil pengujian protokol routing vehicular network dengan parameter uji througphut, dimana pengujian routing protocol ANTC lebih unggul dengan nilai througphut rata - rata $87,758 \mathrm{Kbps}$, pada routing protocol ANT memiliki nilai thtougphut rata - rata $73,163 \mathrm{Kbps}$ dan routing protocol AODV memiliki nilai thtougphut rata - rata 65,844 Kbps.

\section{KESIMPULAN}

Setelah melakukan perancangan, pengembangan serta implementasi algoritma Ant Colony pada Network
Simulator 2.35, serta melakukan pengujian untuk mendapatkan hasil latency dan throughput, maka dapat disimpulkan sebagai berikut:

Berdasarkan tujuan dari penelitian ini dalam melakukan Analisis Performansi pada Protokol Routing Vehicular Network yang terjadi, maka penelitian ini dianggap telah dapat menganalisi performansi protocol routing yang ada pada Vehicular Network. Berdasarkan analisis performansi yang dihasilkan pada penelitian ini menggunakan Algoritma Ant Colony dapat menghasilkan routing ANTC lebih unggul dari routing AODV dan routing ANT dalam perameter uji latency dan throughput. Dan hasil dari analisis performansi protokol routing ANTC menghasilkan nilai dari parameter uji latency dengan nilai rata-rata 16,8 s dan nilai throughput dengan nilai rata-rata $87,758 \mathrm{Kbps}$, Protokol ANT menghasilkan nilai dari parameter uji latency dengan nilai rata-rata $19 \mathrm{~s}$ dan nilai throughput dengan nilai rata-rata $73,163 \mathrm{Kbps}$ sedangkan protocol AODV menghasilkan nilai dari parameter uji latency dengan nilai rata-rata 21,6 s dan nilai throughput dengan nilai rata-rata 73,163 Kbps.

\section{DAFTAR PUSTAKA}

[1] F. Zhang, J. Xi, R. langari, "Real-Time Energy Management Strategy Based on Velocity Forecasts Using V2V and V2 Communications," IEEE Transactions on Intelligent Transportation Systems, Vol. 18, No. 2, pp. 416-430, September 2017.

[2] A. Deshmukh and S. Dorle, "Performance Improvement of Dynamic Source Routing (DSR) Protocol using Ant Colony Optimization for Vehicular Ad-hoc Network (VANet)," International Journal of Scientific Research, vol. 5, no. 1, pp. 171-173, 2016.

[3] Anggraini, Nugroho, and Cahyadi, "Analisis Perbandingan Performasi Protokol Routing AODV Dan DSR Pada Mobile AdHoc Network (MANET)," Tek. Telekomounikasi, Sekol. Tinggi Teknol. Telemat. Telkom, 2017

[4] R. Anisia, R. Munadi and R. M. Negara, "Analisis Performansi Routing Protocol OLSR dan AOMDV pada Vehicular Ad Hoc Network (VANET)," Jurnal Nasional Teknik Elektro, vol. 5, no. 1, pp. 8797, 2016.

[5] Rezky H, Primantara Hari T, Kasyful A, "Implementasi Protokol Geographic Source Routing (GSR) Pada Vecicular Ad-Hoc Network (VANET) untuk Komunikasi Kendaraan dengan Road side Unit (RSU)." Jurnal Pengembangan Teknologi Informasi dan Ilmu Komputer, Universitas Brawijaya, vol. 2, No. 12, pp 7007-7016, Dec. 2018

[6] H. Boeglen, "Analysis of Routing Protocols OLSR, AODV and ZRP in Real Urban Vehicular Scenario with Density Variation," in IEEE Latin America Transctions, Vol. 15, No. 9, pp. 1727-1734, August 2017

[7] A. K. Basil, M. Ismail, M. A. Altahrawi, H. Mahdi, N. Ramli "Performance of AODV and OLSR routing protocol in VANET under various traffic scenarious," in IEEE Malaysia International Conference on Communications, November 2017

[8] F. Goudarzi, H. Asgari, H. Al-Raweshidy, " Traffic-Aware VANET Routing for City Environments A Protocol Based on Ant Colony Optimization," in IEEE Systems Journal, Vol. 13, No. 1, pp. 571 581, March 2018

[9] N. E. Toklu, R. Montemanni, L. M. Gambardella, "A Robust Multiple Ant Colony System For The Capacitated Vehicle Routing Problem," IEEE International Conference On Systems, Man, And Cybernetics, pp. 1871-1876, januari 2014.

[10] Karjono, Moedjiono and D. Kurniawan, "Ant Colony Optimization," Jurnal TICOM, vol. 4, no. 3, pp. 119125,2016.

[11] R.I. Meneguette, L. F. Bittencourt, E. R. M. Madeira, "A Seamless Flow Mobility Management Architecture For Vehicular Communication Networks," Journal of Communication Network, vol. 15, No. 2, pp. 207-216, May 2013. 
[12] C. Clasyson, S. Fabricio, B. Azzedine, M. Rossana, L. Antonio,"Improving VANET Simulation with Calibrate Vehicular Mobility Traces," IEEE Transactions on Mobile Computing, vol. 16, no. 12, pp. 1-13, April 2017.

[13] Q. Wang, P. Fan, K. B. Letaief, " On The Joint V2I and V2V schedulling For Cooperative VANETs With Network Coding," in IEEE Transactions on Vehicular Technology, Vol. 61, No. 1, pp. 62-73, September 2011.

[14] P. Wan, H. Lu, Q. Lu, and N. Luo, "Classification of HighResolution Remote-Sensing Imang Using OpenStreeMap Information," vol. 14, no. 12, pp. 2305-2309, 2017.

[15] M. Laisa, P. Rakh, B. Achmad, "Pengaruh Model Mobilitas Node Pada Protokol Routing AODV dalam MANET," Jurnal Pengembangan Teknologi Informasi dan Ilmu Komputer, Vol. 3, No. 1, pp. 563-572, Januari 2019.

[16] A. Adam, A. Denar, R. Diah, "Analisis Kinerja Jaringan VANET dengan Model Propagasi Free Space dan Two Ray Ground Pada Routing AODV," Vol. 1, No. 2, pp. 69-78, Desember 2019. 